\title{
PENGARUH SELF EFFICACY DAN SELF ESTEEM TERHADAP KINERJA PEGAWAI PADA BADAN PENANGGULANGAN BENCANA DAERAH (BPBD) KOTA PALOPO
}

\author{
Dwi Utami Hasan \\ Email: dwiutamihasan@gmail.com \\ Ekonomi manajemen/ Fakultas Ekonomi/ Univeritas Andi Djemma \\ Jl. Puang Haji Daud No. 4A Kota Palopo \\ Khaerana \\ khaerana.itowotu@gmail.com \\ Ekonomi manajemen/ Fakultas Ekonomi/ Univeritas Andi Djemma \\ Jl. Puang Haji Daud No. 4A Kota Palopo
}

\begin{abstract}
ABSTRAK
Terdapat banyak faktor yang dapat mempengaruhi kinerja seseorang, diantaranya adalah self efficacy dan self esteem. Self efficacy sangat diperlukan dalam meningkatkan kinerja karyawan. Demikian juga dengan self esteem yang dimiliki akan menumbuhkan suatu kekuatan dalam melakukan yang terbaik dalam kinerjanya sesuai tugas dan tanggung jawabnya. Tujuan penelitian ini adalah untuk mengetahui pengaruh positif yang ditimbulkan oleh self efficacy dan self esteem terhadap kinerja pegawai pada Badan Penanggulangan Bencana Daerah (BPBD) Kota Palopo, serta untuk mengetahui variabel yang lebih dominan memberi pengaruh positif terhadap kinerja pegawai pada Badan Penanggulangan Bencana Daerah (BPBD) Kota Palopo. Jenis penelitian ini adalah penelitian kuantitatif dengan teknik pengumpulan data menggunakan kuesioner, wawancara dan observasi, sementara teknik analisis data menggunakan regresi linier berganda. Jumlah Populasi dalam penelitian ini adalah 32 orang pegawai bagian lapangan atau Tim Reaksi Cepat (TRC), karena penentuan jumlah sampelnya menggunakan metode sensus maka sampelnya adalah sejumlah populasi yaitu 32 responden. Hasil penelitian menjunjukkan bahwa nilai $f$ hitung $13,883>$ f table 3,32 dan nilai signifikansi sebesar $0,000<0,05$, sehingga dapat disimpulkan bahwa Self efficacy dan self esteem secara simultan berpengaruh signifikan terhadap kinerja pegawai pada Badan Penanggulangan Bencana Daerah (BPBD) Kota Palopo, dan adapun variable yang lebih dominan berpengaruh terhadap kinerja pegawai adalah self esteem dengan nilai koefisien regresi paling besar yaitu 1,055 , dan nilai standardized coefficient Beta 0,502 dan dari hasil koefisien determinasi diketahui bahwa besarnya kontribusi variable self efficacy dan self esteem mempengaruhi variable kinerja pegawai yaitu sebesar $48,9 \%$, dan sisanya sebesar $51,1 \%$ dipengaruhi oleh faktor lain yang tidak diteliti dalam penelitian ini.
\end{abstract}

Kata Kunci: $\quad$ Kinerja_Pegawai; Self Efficacy; Self Esteem

\section{ABSTRACT}

There are many factors that can affect a person's performance, including self-efficacy and selfesteem. Self-efficacy is very necessary in improving employee performance. Likewise, self-esteem that is owned will grow a strength in doing the best in performance according to their duties and responsibilities. The purpose of this study was to determine the positive effect of self-efficacy and self-esteem on employee performance at the Palopo City Disaster Management Agency (BPBD), and to determine which variables are more dominant and have a positive influence on employee performance at the Regional Disaster Management Agency (BPBD). ) Palopo City. This type of research is quantitative research with data collection techniques using questionnaires, interviews and observations, while the data analysis technique uses multiple linear regression. The number of population in this study were 32 field employees or the Quick Reaction Team (TRC), because the determination of the number of samples used the census method, the sample was a population of 32 respondents. The results showed that the value of $f$ count 13.883> f table 3.32 and a significance value of $0.000<0.05$, so it can be concluded that the simultaneous self-efficacy and self-esteem have a significant effect on employee performance at the Regional Disaster 
Management Agency (BPBD) Palopo City. , and the more dominant variable that has an effect on employee performance is self-esteem with the largest regression coefficient value of 1.055 , and the standardized beta coefficient value is $\mathbf{0 . 5 0 2}$ and from the results of the coefficient of determination it is known that the contribution of self-efficacy and self-esteem variables affects the employee performance variable which is equal to $\mathbf{4 8 . 9 \%}$, and the remaining $51.1 \%$ is influenced by other factors not examined in this study.

Keywords: Employee_performance; Self Efficacy; Self Esteem

\section{PENDAHULUAN}

Manajemen sumber daya manusia memainkan peranan sangat menentukan dalam kehidupan sebuah organisasi. Dalam menjalankan fungsi operasional manajemen sumber daya manusia (MSDM), seorang pemimpin tidak hanya harus mengetahui potensi pegawainya, namun juga diharapkan mampu mendesain sebuah formulasi tertentu yang diaplikasikan pada sumber daya manusia yang ada. Melalui desain yang tepat, diharapkan mampu meningkatkan kinerja para pegawai secara efektif dan efisien sehingga mampu mencapai tujuan organisasi (Hartatik, 2014).

Kinerja adalah serangkaian perilaku individu yang memberikan kontribusi, baik secara positif maupun negatif dalam mencapai tujuan organisasi. (Colquit et al, 2011 dalam Wibowo, 2017). Terdapat beberapa hasil penelitian yang menunjukkan bahwa kinerja individu dapat dipengaruhi oleh banyak faktor, diantaranya self efficacy, sebagaimana yang ditemukan oleh Stajkovic dan Luthans, (1998) dalam Hidayat dan Setiawan (2016), bahwa self efficacy memiliki korelasi signifikan dengan work-related performance. Peneliti lainnya, seperti Rimper dan Karwet (2016), serta Noviawati (2016) juga menemukan adanya pengaruh positif self efficacy terhadap kinerja seseorang. Pendapat senada dikemukakan oleh Moorhead dan Griffin (2013), bahwa individu yang memiliki self efficacy yang tinggi percaya bahwa mereka dapat berkinerja baik dalam menjalankan tugas tertentu. Sebaliknya, individu dengan self efficacy yang rendah cenderung meragukan kemampuannya untuk menjalankan tugas khusus yang dibebankan kepadanya.

Faktor lainnya yang juga memberi pengaruh terhadap kinerja pegawai adalah self esteem. Self Esteem merupakan keyakinan seseorang untuk menilai diri sendiri sehingga dirinya merasa dihargai (Salangka dan Datulong, 2015). Sebagaimana temuan Pratiwi (2015), Sebayang dan Sembiring (2017), serta Widyawati dan Karwini (2018) menunjukkan bahwa self esteem berpengaruh signifikan dalam meningkatkan kinerja pegawai. Sementara temuan berbeda dikemukakan oleh Indrawati (2014) serta Hidayat dan Setiawan (2016) yang 
menyatakan bahwa self esteem tidak memberi pengaruh signifikan terhadap peningkatan Kinerja.

Kota Palopo merupakan salah satu wilayah yang rawan terjadi bencana alam, khususnya banjir dan tanah longsor, mengingat wilayah geografis Kota Palopo terdiri dari perbukitan dan pesisir. Berdasarkan informasi dari Kepala Badan Penanggulangan Bencana Daerah (BPBD) Kota Palopo bahwa terdapat empat kecamatan yang rawan banjir, yakni Wara, Wara Timur,Telluwanua, dan Wara Selatan. Sementara wilayah yang rawan terjadi bencana longsor berada di Kecamatan Mungkajang dan Wara Barat. Sebagai lembaga pemerintah non-departemen yang melaksanakan tugas penanggulangan bencana, diantaranya memberikan early warning bagi masyarakat dan juga memperlancar koordinasi dengan seluruh sektor yang terlibat dalam upaya penanggulangan bencana, BPBD dalam hal ini Tim Reaksi Cepat (TRC) dituntut untuk memiliki kemampuan berkomunikasi serta memahami berbagai penggunaan peralatan yang mendukung tugas mereka di lapangan dan hal ini tentu membutuhkan pelatihan secara rutin agar pegawai memiliki kompetensi atau skill yang memadai untuk menjalankan tugas-tugasnya. BPBD sendiri belum sepenuhnya melakukan program pelatihan secara rutin, padahal proses pelatihan bisa memunculkan keyakinan ataupun kepercayaan diri seseorang dalam mencapai keberhasilan. Selain itu BPBD juga sering melakukan rolling (rotasi) pegawai padahal proses untuk menguasai keahlian tertentu membutuhkan waktu yang lama dan juga butuh pengalaman lapangan yang lebih banyak. Penghargaan berupa pengakuan/pujian dari pimpinan juga bisa memicu keyakinan seseorang untuk berkinerja baik, namun dalam hal ini belum sepenuhnya dirasakan oleh pegawai. Dengan memperhatikan uraian tersebut di atas sehingga menarik untuk dilakukan penelitian yang berjudul Pengaruh Self Efficacy dan Self Esteem terhadap Kinerja Pegawai pada Badan Penganggulangan Bencana Daerah (BPBD) Kota Palopo.

\section{METODE PENELITIAN}

Penelitian ini dilakukan pada Tahun 2020 di Kantor Badan Penanggulangan Bencana Daerah (BPBD) Kota Palopo. Populasi dalam penelitian ini sebanyak 32 orang pegawai dan teknik pengambilan sampel dengan metode sensus, dimana semua populasi dijadikan sampel (Sugiyono, 2015). Jenis penelitian yang digunakan adalah penelitian kuantitatif dengan teknik pengumpulan data melalui sumber data primer yaitu memberikan kusioner langsung kepada responden, dan sumber data sekunder, yaitu melalui literatur, jurnal, artikel media online ataupun dokumen terkait lainnya. 


\section{ANALISIS DATA}

\section{Uji InstrumenPenelitian}

a. UjiValiditas

Uji validitas bertujuan untuk mengukur valid atau tidaknya suatu instrumen, dengan membandingkan nilai $r$ hitung dan $r$ table, jika $r$ hitung $>r$ tabel, maka instrumennya valid, sedangkan jika $r$ hitung < r tabel, maka tidak valid.

b. Uji Reliabilitas

Uji reliabilitas digunakan untuk mengetahui konsistensi alat ukur (instrumen), apakah alat ukur tersebut dapat diandalkan dan tetap konsisten, reliabel jika nilai Cronbach Alfa >0,6.

\section{Uji Asumsi Klasik}

Uji asumsi klasik merupakan persyaratan statistik yang harus dipenuhi pada analisis regresi linear berganda. Uji Asumsi klasik meliputi Uji Normalitas, Uji Multikolinearitas, dan Uji Heteroskedastisitas.

\section{Analisis Regresi Linier Berganda}

a. Metode analisis regresi linier berganda melalui program komputer SPSS 20.00 dengan rumus:

$$
Y=b_{0}+b_{1} X_{1}+b_{2} X_{2}+\varepsilon
$$

Dimana:

$$
\begin{array}{ll}
\mathrm{Y} & =\text { Kinerja Pegawai } \\
\mathrm{X} 1 & =\text { Self Efficacy } \\
\mathrm{X} 2 & =\text { Self Esteem } \\
\mathrm{b}_{1-2} & =\text { Koefisien regresi } \\
\mathrm{b}_{0} & =\text { Konstanta } \\
\mathrm{e} & =\text { standar error }
\end{array}
$$

b.Uji Koefisien Determinasi $\left(\mathrm{R}^{2}\right)$

Untuk mengukur kontribusi variable independen (bebas) terhadap variable dependen (terikat) dapat ditentukan dengan rumus koefisien diterminan yaitu sebagai berikut:

$$
\begin{aligned}
& K P=R^{2} x 100 \% \\
& \text { dimana: } \\
& \mathrm{KP}=\text { Koefisien determinasi } \\
& \mathrm{R}^{2}=\text { Koefisien korelasi }
\end{aligned}
$$




\section{c. UjiSimultan (Uji-F)}

Uji-f digunakan untuk mengetahui pengaruh secara bersama-sama (simultan) variable bebas terhadap varibel terikat. Dengan ketentuan, jika f-hitung > f-tabel, maka hipotesis diterima. Sebaliknya, jika f-hitung<f-tabel, maka hipotes is ditolak.

d.UjiParsial(Uji-T)

Uji-t digunakan untuk mengetahui apakah masing-masing variable bebas secara parsial berpengaruh secara signifikan terhadap variable terikat. Dengan ketentuan thitung $>\mathrm{t}$ - tabel maka hipotesis diterima, sebaliknya jika t-hitung < t-tabel, maka hipotesis ditolak.

\section{HASIL DAN PEMBAHASAN}

\section{Hasil}

\section{a. Uji Validitas}

Setelah dilakukan pengujian dengan membandingkan $\mathrm{r}$ hitung $>\mathrm{r}$ table, dari 12 item pernyataan untuk variable X1 (Self Efficacy) dengn tingkat validitas antara 0,434 0,715 dan $\mathrm{r}$ table $=0,361$, jadi bisa disimpulkan bahwa semua item pernyataan dinyatakan valid, dan untuk variable X2 (self Esteem) dari 10 pernyataan ada 2 item pernyataan yang tidak valid karena nilai $r$ hitung kurang dari 0,361 dan 8 item pernyataan dinyatakan valid dengan tingkat validitas antara 0,387 - 0,849, selanjutnya untuk variable y (Kinerja Pegawai) dengan 14 item pernyataan kesemuanya dinyatakan valid karena tingkat validitasnya antara $0,517-0,875$.

\section{b. Uji Realibilitas}

Hasil pengujian reliabilitas yang dilakukan dari total 34 item pernyataan dari ketiga variable dengan nilai cronnbach's alpha antara 0,769-0,929>0,60, sehingga dapat disimpulkan bahwa semua item pernyataan dari ketiga variable tersebut dinyatakan reliabel.

\section{c. Uji Asumsi Klasik}

Uji asumsi klasik merupakan persyaratan statistik yang harus dipenuhi pada analisis regresi linear berganda, dengan beberapa asumsi yang diuji, diantaranya adalah:

1. Uji Normalitas dengan Kolmogrof Smirnov

Tabel 1 Uji Normalitas Kolmogorov-Smirnov Test

\begin{tabular}{|ll|r|}
\hline \multicolumn{2}{|c|}{ One-Sample Kolmogorov-Smirnov Test } \\
\hline N & Unstandardized Residual \\
Normal Parameters ${ }^{\text {a,b }}$ & Mean & 32 \\
& Std. Deviation & $0 \mathrm{E}-7$ \\
\hline
\end{tabular}




\begin{tabular}{|ll|r|} 
& Absolute & .090 \\
Most Extreme Differences & Positive & .090 \\
& Negative & -.083 \\
Kolmogorov-Smirnov Z & & .511 \\
Asymp. Sig. (2-tailed) & & .957 \\
\hline
\end{tabular}

a. Test distribution is Normal.

b. Calculated from data.

Sumber: data diolah 2020

Pada table 1 tersebut di atas diperoleh nilai signifikasi 0,957>0,05 maka dapat disimpulkan bahwa nilai residual terdistribusi normal, sehingga uji asumsi normalitas telah terpenuhi.

2. Uji multikolenieritas (Metode Tollerance dan FIV)

Tabel 2 Uji Multikolenieritas

\begin{tabular}{|c|c|c|c|c|c|c|c|c|}
\hline \multirow{2}{*}{\multicolumn{2}{|c|}{ Model }} & \multicolumn{2}{|c|}{$\begin{array}{c}\text { Unstandardized } \\
\text { Coefficients }\end{array}$} & \multirow{2}{*}{$\begin{array}{c}\begin{array}{c}\text { Standardized } \\
\text { Coefficients }\end{array} \\
\text { Beta }\end{array}$} & \multirow[t]{2}{*}{$\mathrm{t}$} & \multirow[t]{2}{*}{ Sig. } & \multicolumn{2}{|c|}{ Collinearity Statistics } \\
\hline & & $\mathrm{B}$ & Std. Error & & & & Tolerance & VIF \\
\hline \multirow{3}{*}{1} & (Constant) & 3.479 & 10.122 & & .344 & .734 & & \\
\hline & $\begin{array}{l}\text { SELF } \\
\text { EFFICACY }\end{array}$ & .434 & .227 & .295 & 1.915 & .065 & .741 & 1.349 \\
\hline & $\begin{array}{l}\text { SELF } \\
\text { ESTEEM }\end{array}$ & 1.055 & .324 & .502 & 3.254 & .003 & .741 & 1.349 \\
\hline
\end{tabular}

a. Dependent Variable: KINERJA PEGAWAI

Sumber: Data diolah 2020

Berdasarkan table 2 tersebut di atas diperoleh nilai tolerance untuk variable X1 dan $\mathrm{X} 2=0,741>0,100$ dan nilai VIF $=1,349<10,00$, maka danyatakan bahwa tidak ada gejala multikolenieritas dan tidak terdapat korelasi antar variabel independen.

3. Uji Heterokedastisitas dengan menggunakan Metode Gletzer

Tabel 3 Uji Heterokedastisitas Metode Gletzer

Coefficients $^{\mathrm{a}}$

\begin{tabular}{|rl|r|r|r|r|r|}
\hline \multicolumn{2}{|l|}{} & \multicolumn{2}{|c|}{ Unstandardized Coefficients } & \multicolumn{1}{c|}{$\begin{array}{c}\text { Standardized } \\
\text { Coefficients }\end{array}$} & \multirow{2}{*}{ Sig. } \\
\cline { 3 - 5 } & & \multicolumn{2}{|c|}{ B } & Std. Error & \multicolumn{1}{c|}{ Beta } & \\
\hline \multirow{2}{*}{1} & (Constant) & 8.307 & 5.422 & & 1.532 & .136 \\
& SELF EFFICACY & -.179 & .122 & -.306 & -1.469 & .153 \\
& SELF ESTEEM & .123 & .174 & .147 & .705 & .486 \\
\hline
\end{tabular}

a. Dependent Variable: abs_Res

Sumber: Data diolah 2020

Berdasarkan table 3 tersebut di atas dapat disimpulkan bahwa tidak terjadi masalah heterokedastisitas, dibuktikan dengan nilai signifikan variable Self Efficacy (X1) = 0,153 > 0,05, dan Self Esteem $(\mathrm{X} 2)=0,486>0,05$.

\section{d. Analisis Regresi Berganda}

1. Uji f (Uji Simultan) 
Uji fdigunakan untuk mengetahui pengaruh variabel independen secara bersamasama (simultan) terhadap variable dependen. Uji F dilakukan dengan membandingkan nilai $\mathrm{f}$ hitung dengan nilai $\mathrm{f}$ table atau dengan nilai signifikan $<0.05$.

Tabel 4 Analisis Varian (Anova)

\begin{tabular}{|rl|r|r|r|r|r|}
\hline Model & & Sum of Squares & Df & Mean Square & F & \multicolumn{1}{c|}{ Sig. } \\
\hline \multirow{3}{*}{1} & Regression & 705.432 & 2 & 352.716 & 13.883 & $.000^{\mathrm{b}}$ \\
& Residual & 736.787 & 29 & 25.406 & & \\
& Total & 1442.219 & 31 & & & \\
\hline
\end{tabular}

a. Dependent Variable: KINERJA PEGAWAI

b. Predictors: (Constant), SELF ESTEEM, SELF EFFICACY

Sumber: Data diolah 2020

Berdasarkan table 4 tersebut di atas diperoleh nilai f hitung $=13,883>\mathrm{f}$ table 3,32 dan nilai signifikansi sebesar $0,000<0,05$, hal tersebut menunjukkan bahwa secara simultan self efficacy dan self esteem berpengaruh positif dan signifikan terhadap kinerja pegawai pada Badan Penanggulangan Bencana Daerah (BPBD) Kota Palopo, sehingga dapat disimpulkan bahwa hipotesis pertama diterima.

2. Uji t (Parsial)

Uji-t digunakan untuk mengetahui apakah masing-masing variable independen secara parsial berpengaruh secara signifikan terhadap variable dependen, dengan membandingkan nilai t-hitung $>$ t- table, dan nilai signifikansi $<0.05$

Tabel 5 Uji t (Uji Parsial)

Coefficients $^{\text {a }}$

\begin{tabular}{|c|c|c|c|c|c|c|}
\hline \multirow{2}{*}{\multicolumn{2}{|c|}{ Model }} & \multicolumn{2}{|c|}{ Unstandardized Coefficients } & \multirow{2}{*}{$\begin{array}{c}\begin{array}{c}\text { Standardized } \\
\text { Coefficients }\end{array} \\
\text { Beta }\end{array}$} & \multirow[t]{2}{*}{$\mathrm{t}$} & \multirow[t]{2}{*}{ Sig. } \\
\hline & & B & Std. Error & & & \\
\hline \multirow{3}{*}{1} & (Constant) & 3.479 & 10.122 & & .344 & .734 \\
\hline & SELF EFFICACY & .434 & .227 & .295 & 1.915 & .065 \\
\hline & SELF ESTEEM & 1.055 & .324 & .502 & 3.254 & .003 \\
\hline
\end{tabular}

a. Dependent Variable: KINERJA PEGAWAI

Sumber: Data diolah 2020

Berdasarkan table 5 di atas diperoleh nilai t hitung untuk Self Efficacy (X1) = $1,915<2,042$ dan nilai signifikansi sebesar 0,065>0,05, jadi dapat diartikan bahwa Self Efficacy (X1) tidak berpengaruh signifikan terhadap Kinerja pegawai (Y). Sementara untuk Self Esteem (X2) diperoleh nilai t hitung = 3,254 > 2,042 dan nilai signifikansinya sebesar $0,003<0,05$, jadi dapat dimaknai bahwa Self Esteem (X2) berpengaruh positif dan signifikan 
terhadap kinerja pegawai (Y). Berdasarkan hasil olah data tersebut di atas maka diperoleh persamaan regresi sebagai berikut:

$$
\mathrm{Y}=3,479+0,434 \mathrm{X} 1+1,055 \mathrm{X} 2
$$

Interpretasi dari persamaan regresi linear berganda tersebut di atas dapat diuraikan sebagai berikut:

a. Nilai Konstanta sebesar 3,479 menunjukkan bahwa jika variable self efficacy dan self esteem seluruhnya dianggap konstan atau sama dengan nol, maka kinerja pegawai akan tetap sebesar 3,479.

b. Koefisien regresi untuk variable self efficacy (X1) sebesar 0,434 menunjukkan bahwa dengan meningkatnya variable self efficacy (X1) sebesar 1 satuan maka akan meningkatkan kinerja pegawai sebesar 0,434 dengan asumsi variable lain tidak mengalami perubahan atau konstan.

c. Koefisien regresi untuk variable Self esteem (X2) sebesar 1,055 menunjukkan bahwa dengan meningkatnya variable self esteem 1 satuan maka akan meningkatkan kinerja pegawai sebesar 1,055 dengan asumsi variable lain tidak mengalami perubahan atau konstan.

Berdasarkan hasil olah data tersebut maka dapat dismpulkan bahwa variable self esteem lebih dominan berpengaruh terhadap kinerja pegawai Badan Penanggulangan Bencana Daerah (BPBD) Kota Palopo, hal ini dibuktikan dengan nilai koefisien regresi lebih besar yaitu 1,055 dan nilai Standardized Coefficients beta 0,502, dengan demikian hipotesis kedua dalam penelitian ini diterima.

3. Uji Koefisien Determinasi $\left(\mathrm{R}^{2}\right)$

Koefisien determinasi digunakan untuk mengukur kontribusi variable independen (bebas) terhadap variable dependen (terikat).

Tabel 6 Koefisien determinasi (Model Summary)

\begin{tabular}{|l|r|r|r|r|}
\hline Model & \multicolumn{5}{|c|}{ R } & \multicolumn{1}{|c|}{ R Square } & Adjusted R Square & \multicolumn{1}{c|}{ Std. Error of the Estimate } \\
\hline 1 & $.699^{\mathrm{a}}$ & .489 & .454 & 5.040 \\
\hline
\end{tabular}

a. Predictors: (Constant), SELF ESTEEM, SELF EFFICACY

Sumber: Data diolah (2020)

Berdasarkan table 6 tersebut di atas dapat disimpulkan bahwa kontribusi variable self efficacy dan self esteem mempengaruhi kinerja pegawai sebesar 0,489 atau 48,9\%, dan sisanya sebesar $51,1 \%$ dipengaruhi oleh variable lain yang tidak diteliti dalam penelitian ini. 


\section{Pembahasan}

Setelah dilakukan pengujian secara simultan maupun parsial di mana variable self efficacy dan self esteem secara simultan berpengaruh signifikan terhadap kinerja pegawai pada Kantor Badan Penanggulangan Bencana Daerah (BPBD) Kota Palopo, dan secara parsial variable self esteem yang lebih dominan berpengaruhh positif dan signifikan terhadap kinerja pegawai pada Kantor BPBD Kota Palopo, maka dapat diuraikan sebagai berikut:

1. Pengaruh Self Efficacy Terhadap Kinerja Pegawai

Self efficacy adalah kepercayaan seseorang terhadap kemampuannya untuk melakukan tugas yang spesifik. Self efficacy muncul dalam diri seseorang secara bertahap bisa melalui pengalaman atau pun kemampuan kognitifnya, juga melalui proses interaksi sosial, serta keterampilan fisik yang lebih kompleks. Hasil analisis secara deskriptif variable self efficacy menunjukkan bahwa self efficacy pegawai BPBD Kota Palopo sudah tergolong baik, di mana hal ini didukung oleh pegawai merasa mampu melakukan pekerjaannya, pegawai memiliki kemampuan yang lebih baik, pegawai senang pekerjaan yang menantang, dan pegawai selalu merasa puas terhadap pekerjaannya. Meski pun self efficacy yang dimiliki oleh pegawai BPBD Kota Palopo sudah tergolong baik namun belum memberi pengaruh yang signifikan terhadap kinerja mereka, sehingga dibutuhkan perhatian dari pimpinan agar lebih memaksimalkan kemampuan pegawainya untuk melaksanakan tugas-tugas yang spesifik agar lebih meningkatkan kinerjanya ke depan dan lebih memudahkan dalam proses pencapaian tujuan. Dimana, dilihat dari segi pekerjaan pegawai dalam hal ini Tim Reaksi Cepat (TRC) BPBD yang memang sangat menantang di lapangan, karena harus berhadapan dengan kejadian bencana alam dan juga tata cara penanggulangannya yang memang membutuhkan keahlian khusus.

2. Pengaruh Self Esteem Terhadap Kinerja Pegawai

Seseorang dengan self esteem yang tinggi dimana mereka melihat dirinya berharga, mampu dan dapat diterima. Seseorang dengan self esteem rendah tidak merasa baik dengan dirinya sehigga cenderung mempengaruhi kinerjanya. Karena self esteem menggambarkan sejauh mana individu tersebut menilai dirinya sebagai orang yang memiliki kemampuan, keberartian, berharga dan kompeten. Hasil penelitian ini membuktikan bahwa dengan semakin meningkatnya self esteem maka akan meningkatkan kinerja pegawai pada Kantor BPBD Kota Palopo. Hal ini memperkuat hasil temuan Sebayang dan Sembiring (2017) serta Widyawati dan Karwini (2018) di 
mana hasil penelitiannya menyatakan bahwa terdapat pengaruh positif dan signifikan self esteem terhadap kinerja pegawai, atau dengan kata lain, semakin baik self esteem yang dimilki oleh seorang pegawai maka akan semakin meningkatkan kinerjanya, sebaliknya semakin buruk self esteem yang dimiliki oleh seorang pegawai maka akan menurunkan kinerjanya. Sebagaimana diperkuat oleh Kreitner\& Kinicki (2003) dalam Trisanto (2017) bahwa perasaan-perasaan self esteem, pada kenyataannya terbentuk oleh keadaan kita dan bagaimana orang lain memperlakukan kita. Namun berbeda dengan temuan Indrawati (2014) serta Hidayat dan Setiawan (2016) yang menyatakan bahwa self esteem tidak memberi pengaruh signifikan terhadap peningkatan kinerja.

\section{KESIMPULAN}

Berdasarkan hasil analisis dan pembahasan maka dismpulkan bahwa self efficacy dan Self esteem secara simultan berpengaruh positif dan signifikan terhadap kinerja pegawai pada Kantor Badan Penanggulangan Bencana Daerah (BPBD) Kota Palopo. Sementara itu dari hasil penelitian ini juga diketahui juga bahwa variable Self esteem yang lebih dominan berpengaruh terhadap kinerja pegawai. Dengan semakin meningkatnya Self Esteem yang dimiliki oleh seorang pegawai maka akan semakin meningkatkan kinerjanya.

\section{DAFTAR PUSTAKA}

Chasanah, N. 2008. Analisis Pengaruh Empowerpoint, Self efficacy dan Budaya Organisasi Terhadap Kepuasan Kerja Karyawan Dalam Meningkatkan Kinerja Karyawan (Studi Empiris pada Karyawan PT. Mayora Tbk Regional Jateng dan DIY) [Tesis]. Semarang (ID): Universitas Diponegoro Semarang

Hartatik, Indah Puji. 2014. Buku Praktis Mengembangkan SDM. Cetakan Pertama. Jakarta: Laksana

Hidayat, Herman dan Setiawan I, Aries. 2016. Pengaruh Self Esteem dan Self Efficacy Terhadap Kinerja Karyawan (Studi pada Karyawan PT. Tomo Food Industri, Sumedang). Jurnal Sains Manajemen dan Akuntansi, VIII (2): 1 - 9

Indrawati, Y. 2014. Pengaruh Self Esteem, Self Efficacy dan Kepuasan Kerja Terhadap Kinerja Karyawan: Studi Kasus Perawat RS. Siloam Manado. Jurnal Riset Bisnis dan Manajemen, 2 (4):12-24.

Kaseger, Regina Gledy. 2013. Pengembangan Karir dan Self Efficacy Terhadap Kinerja Karyawan pada PT. Matahari Department Store Manado Town Square. Jurnal EMBA, 1 (4): 906-916.

Kilapong S, Novian (2013), Kepemimpinan Transformasional, Self Efficacy, Self Esteem Pengaruhnya Terhadap Kepuasan Kerja Karyawan. Jurnal EMBA. 1 (4): 141-150

Lestari W, Puji dan Afifah D, Ratnaningtyas. 2014. Pengaruh Self Efficacy dan Kecerdasan Emosi Terhadap Motivasi Berprestasi Siswa SMK PGRI 1 Madiun. Jurnal Bimbingan Konseling, 4 (2) 
Moorhead dan Griffin, 2013. Prilaku Organisasi. Jakarta: Salemba Empat

Noviawati D, Rizki. 2016. Pengaruh Self Efficacy Terhadap Kinerja Karyawan Dengan Motivasi Sebagai Variabel Intervening (Studi Pada Karyawan Divisi Finance Dan Divisi Human Resource PT. Coca-Cola Distribution Indonesia, Surabaya).Jurnal Ilmu Manajemen (JIM). 4 (3): 1 - 12

Pratiwi, Amelia Dwi. 2015. Pengaruh Self Esteem, Self Efficacy dan Kepuasan Kerja Terhadap Kinerja Individual Pada PT. Pegadaian Persero Jakarta (Studi Kasus di PT. Pegadaian Jakarta). Universitas Islam Indonesia, Fakultas Ekonomi Yogyakarta.

Purnomo, Retno dan Lestari, Sri. 2010. Pengaruh Kepribadian, Self-Efficacy, dan Locus Of Control Terhadap Persepsi Kinerja Usaha Skala Kecil dan Menengah. Jurnal Bisnis dan Ekonomi (JBE). 17 (2): 144 - 160

Rimper R, Ribka., dan Karwet, Lotje. 2014. Pengaruh Perencanaan Karir dan Self Efficacy Terhadap Kinerja Karyawan pada PT. PLN (PERSERO) Area Manado. Jurnal $E M B A, 2$ ( 4): 413-423.

Salangka, R, dan Dotulong, L. 2015. Pengaruh Self Efficacy, Self Esteem dan Lingkungan Kerja Terhadap Kepuasan Kerja Karyawan pada PT. PLN (Persero) Wilayah Suluttenggo. Jurnal EMBA. 3 (3): 562 - 572

Santoso, Singgih. 2017. Menguasai Statistik dengan SPSS 24. Jakarta: PT. Gramedia

Sapariyah, Rina Ani. 2011. Pengaruh Self Esteem, Self Efficacy and Locus of Control Terhadap Kinerja dalam Perspektif Balanced Scorecard pada PERUM Pegadaian Boyolali. ProBank, 1 (7): 1-13.

Sebayang, Stevani dan Sembiring, Jafar. 2017. Pengaruh Self Esteem dan Self Efficacy Terhadap Kinerja Karyawan (Studi Kasus di PT. Finnet Indonesia). e-Proceeding of Management, 4 (1): 335-345

Sugiyono.2015.Metode Penelitian Manajemen.Cetakan ke-4.Bandung:Alfabeta.

Sunyoto,Danang dan Burhanudin.2015.Teori Perilaku Keorganisasian. Cetakan Pertama. J akarta:CAPS (Center for Academik PublishingService)

Suparyadi, H. 2014. Manajemen Sumber Daya Manusia - Menciptakan Keunggulan Bersaing Berbasis Kompetensi SDM. Ed. I. Yogyakarta: Andi.

Syaifuddin. 2018. Motivasi \& Kinerja Pegawai (Pendekatan Riset). Edisi Pertama.. Sidoarjo: Indomedia Pustaka

Trisanto A, Angga. 2017. Pengaruh Self Esteem dan Self Efficacy Terhadap Kinerja Karyawan PT. Danliris Sukoharjo. Fakultas Ekonomi dan Bisnis Universitas Muhammadiyah Surakarta

Wibowo. 2017. Manajemen Kinerja. Cetakan ke-12. Depok: Rajawali Pers.

Widiyawati, S. Rini dan Karwini, Ni Ketut. 2018. Pengaruh Self Esteem, Self Efficacy dan Keterlibatan Kerja terhadap Kinerja Karyawan pada PT. Dwi Fajar Semesta Denpasar. Forum Manajemen, 16 (2): 265-377.

Yanti, N, Nurtati dan Misharni (2020). Investasi Modal Manusia Bidang Pendidikan: Dampak Pengangguran dan Pertumbuhan Ekonomi. Jurnal Ekonomi Pembangunan (JEP), 6 (2): $21-37$ 